\title{
LA ENSEÑANZA DE LA FILOSOFÍA COMO LUCHA POR EL PENSAMIENTO. REFLEXIONES A PARTIR DEL TEXTO "EL ROL DE LA FILOSOFÍA EN EL DESARROLLO DEL PENSAMIENTO CRÍTICO” DE SYLVIA EYZAGUIRRE
}

\author{
Marcela Gaete Vergara \\ Universidad de Chile \\ magaete@uchile.cl
}

RR El texto "El rol de la filosofía en el desarrollo del pensamiento crítico" transita a través de argumentos basados en la evidencia científica, para sostener la urgente necesidad de incorporar la enseñanza de la filosofía desde los primeros años de la Enseñanza Básica en el currículo escolar, pues, como señala Eyzaguirre, en diversas investigaciones nacionales e internacionales se habría concluido el impacto que ésta tendría en el desarrollo de habilidades cognitivas como la argumentación, el pensamiento crítico, la comprensión lectora, pero además, en la confianza de los estudiantes para hablar en público, escuchar y en su autoestima.

Investigaciones en relación con el desarrollo del pensamiento crítico están disponibles hace bastante tiempo, incluso el marco curricular adhiere a su fomento, por ello, vale preguntarse por qué la resistencia con la clase de filosofía, no solo al no ser considerada en el currículo de Enseñanza Básica, técnico profesional y educación artística, sino en la reciente intención de eliminarla del plan común de la enseñanza científico-humanista, dejándola como curso electivo solo para pocos alumnos, cuestión que fue revertida por la lucha de las redes de profesores y académicos de filosofía y por la sociedad en general, que rechazó con fuerza la iniciativa.

Veamos. Si una sociedad tiene como pretensión que todos los estudiantes adquieran los conocimientos mínimos obligatorios y las habilidades necesarias que le permitan insertarse en el mundo actual y diversos estudios revelan que "los niños que tuvieron filosofía progresaron aproximadamente dos meses más que el resto de los estudiantes en lectura y matemáticas, sobre todo alumnos prioritarios (Eyzaguirre 2018, p. 6), entonces, por qué quienes toman las decisiones curriculares no abrazan con entusiasmo la incorporación de filosofía desde primero básico.

Eyzaguirre argumenta desde la vereda paradigmática de una educación para el desarrollo de habilidades cognitivas y ciudadanas necesarias para adaptarse al mundo actual, misma vereda por la que transitan los argumentos de las políticas públicas en materia educativa. Ante dicha coherencia pareciera que nadie podría dudar de los beneficios del aprendizaje de la filosofía desde la más temprana edad y, menos aún, podría pensar en eliminarla de la enseñanza media. Pero sabemos que esto no ha sido así a lo largo de la historia del sistema educativo chileno, donde la enseñanza de la filosofía se ha visto reducida, eliminada o licuada hacia asignaturas como psicología, 
lógica o formación en ciudadanía. Cabe preguntarse entonces, cuáles son las verdaderas razones de la marginalidad de la filosofía en el currículo escolar.

A mi juicio, Silvia Eyzaguirre desliza algunas afirmaciones e interrogantes del ámbito de la filosofía de la educación que son centrales para comprender la marginalidad que ha tenido la filosofía en el currículo escolar. Argumentaciones que escapan a los fervientes beneficios de la clase de filosofía para el desarrollo cognitivo y ciudadano que, si bien podrían convencer a los técnicos de la educación que corren en busca de resultados, no convencen a quienes toman las decisiones políticas. La autora señala: "La educación no sólo cumple un rol fundamental en lo que respecta al desarrollo humano, sino también juega un papel político, económico, social y cultural fundamental" (p. 2). Debemos preguntarnos, entonces, cuál es en realidad el rol político, económico, social y cultural que se atribuye a la filosofía, entre quienes toman las decisiones curriculares, que constantemente le otorgan un lugar marginal en la formación de sujetos/as y en la configuración de la subjetividad? Sí, porque la escuela produce sujetos/as (Foucault) y configura subjetividades (Tenti 1998) y no solo provoca aprendizajes específicos. Así, un estudiante puede egresar con escasos conocimientos en inglés, matemática, ciencias, lenguaje, u otros, pero doce años transitados por la escuela, ocho horas diarias, inciden irremediablemente en la configuración de su identidad, en el lugar que cree o puede optar en el mundo, en sus expectativas y posibilidades de futuro y en ciertas visiones de sociedad y de la realidad.

Así, intentar responder a las preguntas que señala Eyzaguirre (2018, p. 2), a saber, "¿cómo educar a las nuevas generaciones para que puedan enfrentar un mundo desconocido? o ¿cómo debemos educar para que nuestras futuras generaciones puedan desenvolverse en el mundo del mañana?", con evidencias del valor de la clase de filosofía para el desarrollo de habilidades altamente requeridas, es un camino lógico, pero sin retorno, pues la filosofía - todos lo sabemos- no solo fomenta dichas habilidades sino que posibilita la apertura del pensamiento, el abrir la mirada a otras visiones de mundo, a otras formas de entender la realidad y la sociedad, en definitiva, posibilita la configuración de una subjetividad otra. Esto último es lo que se calla como argumento en la insistencia de eliminar, disminuir y no ampliar la enseñanza de la filosofía en la escuela, es decir, al negar a algunos -el $80 \%$ de la población que asiste a las escuelas municipales y particulares subvencionadas que se rigen por el currículo obligatoriodichas posibilidades.

No podemos negar, entonces, las intensas relaciones entre filosofía, educación y política. En este sentido, la enseñanza de la filosofía en la escuela excede a la propia disciplina y la resitúa en el contexto sociohistórico de los actores de la educación, anteponiendo a las tradicionales preguntas qué y cómo enseñar, las interrogantes para qué educar a "ciertos" quiénes. Es así como ese para qué va cambiando si se trata de educar a las clases privilegiadas o las más pobres. Las primeras siempre han valorado la enseñanza de la filosofía, lo que se traduce en que en muchas escuelas particulares pagadas en Chile dictan filosofía con niños desde la Enseñanza Básica, y no haya estado nunca en sus planes eliminarla de la Enseñanza Media. 
Un estudio que realicé hace 10 años sobre el currículo escolar de filosofía (Gaete 2007) desde el siglo XIX a la fecha, visibilizó que en la medida en que se masifica la Enseñanza Media en Chile y las clases altas dejan de asistir a la escuela pública, la asignatura de filosofía cada vez más, introdujo propósitos menos reflexivos y críticos, y aumentó contenidos que parecen más útiles, como los que propone el programa de Tercero Medio actual en relación a sexualidad y enfermedades mentales o el de Cuarto Medio en torno a la moral, que promueve cierto tipo de conductas en sociedad. La pregunta es si ese tratamiento en el que la filosofía es un medio para ciertas finalidades sociales, que los escolares no pueden poner en cuestión ni problematizar, realmente desarrolla un pensamiento crítico, que permita "distinguir los supuestos sobre los cuales se construyen las teorías y cuestionarlos, evaluar la robustez de la evidencia y la solidez de los argumentos, reconocer los límites de la evidencia y el grado de certeza de las conclusiones, advertir las falencias y el alcance de la capacidad prescriptiva. El razonamiento crítico no sólo crea conocimiento positivo, sino que además reflexiona críticamente sobre éste" (Eyzaguirre 2018, p. 4).

$\mathrm{Al}$ respecto me aventuro a interpretar que, a pesar de las bondades de la clase de filosofía en el desarrollo de habilidades cognitivas de orden superior, y su colaboración en el mejor aprendizaje de las áreas de lenguaje y matemática se teme a sus efectos colaterales, pues el desarrollo del pensamiento crítico no refiere solo a la habilidad de argumentar, sino al contenido de esa argumentación.

Los beneficios de la filosofía no se limitan, sin embargo, a su impacto en el desarrollo de habilidades cognitivas y no cognitivas, sino que también permite abordar cuestiones que son fundamentales para el desarrollo humano y la formación ciudadana, a saber, la pregunta por la realidad, la verdad y el conocimiento (epistemología), por el bien y la justicia (ética) y por nuestra propia existencia (antropología filosófica y ontología) (Eyzaguirre 2018, p. 4).

Preguntas fundamentales que, a mi juicio, pueden poner de cabeza muchas supuestas verdades en las que hemos sido formados. Tomaré algunas de las preguntas que señala Eyzaguirre (2018, p. 7), a saber: ¿Cuál es la diferencia entre realidad y apariencia? ¿La distinción entre realidad y apariencia no supone ya un determinado punto de vista? ¿Cómo nos comprendemos? ¿Somos libres? ¿En qué consiste la libertad? ¿Cuáles son los criterios que deben guiar nuestra propia conducta? ¿Cuáles son los fundamentos de dichos criterios? Y podría agregar otras preguntas: ¿Por qué ciertos saberes son considerados válidos y otros no? ¿La organización social en la que vivimos es la más justa? ¿A quién beneficia y a quiénes margina? ¿Existen otros modos de habitar el mundo? ¿Cuál es la cosmovisión del mundo en que hemos sido formado y qué consecuencias éticas y políticas conlleva?

Formarnos desde pequeños en el pensamiento crítico y en la argumentación que lo concretiza implica formarnos en la capacidad de problematizar el mundo en que vivimos, en el derecho a construir nuestros propios contenidos, generar voz propia, preguntarnos y cuestionar los marcos referenciales en que hemos sido socializados, transitar hacia la construcción de nuestras propias visiones de mundo y de sociedad, pues si bien muchas preguntas filosóficas son universales, su concreción en respuestas 
especificas son siempre sociohistóricas, de allí que se pueda hablar de una filosofía griega, francesa, alemana, las que también contienen interrogantes particulares. Así, no solo la filosofía pregunta, sino que también ha desarrollado ciertas respuestas, que siempre, por tanto, devienen en contenido. La filosofía es contenido. No son lo mismo los contenidos de Platón, Aristóteles, Descartes, Nietzsche, Marx, Foucault, Ana Arendt, Simone de Beauvoir, Dussel, Giannini, aunque todos/as puedan haber desarrollado un pensamiento crítico, una argumentación o haberse hecho preguntas similares.

Me parece que en un mundo donde los saberes también son una mercancía, la escuela se transforma en el lugar de transacción de saberes-instrumentos utilizables por los clientes escolares (Tardif 2004), el espacio escolar se transforma en el lugar para vender/reproducir un tipo de sociedad, donde los saberes que no representan un potencial margen de utilidad que garantice el mantenimiento social y el progreso de los grupos económicos van quedando paulatinamente fuera, como en el caso de filosofía, que no queda fuera porque no desarrolle habilidades cognitivas de pensamiento crítico, sino porque de pasada podría desarrollar posibilidades otras de pensamiento.

Si bien comparto las conclusiones del texto de Eyzaguirre, me parece que lo relevante no solo es desarrollar la filosofía en la escuela, sino preguntarnos qué filosofía queremos desarrollar, pues cuando nos preguntamos esto, ponemos el acento no solo en las habilidades sino en el contenido, en el qué, resignificado sociohistóricamente desde las preguntas para qué y para quiénes. Trabajos de Joaquín Barceló (1982), Cecilia Sánchez (1992) y José Santos (2015) nos advierten que la enseñanza institucional de la filosofía podría no ser tan crítica y reflexiva como podríamos pensar. Debemos tener presente que en Chile, casi la única forma de aprender filosofía es al interior de instituciones escolares y universitarias, en las cuales su enseñanza se hace a través de un currículo, que determina una cierta forma de enfocar los contenidos y los propósitos, los que podrían limitarse, como dice Barceló (1982), a repetir el pensamiento de los filósofos europeos y cultivarla como una disciplina a la distancia, como plantea Cecilia Sánchez (1992), o mantenerla dentro de determinados cauces normales institucionales, lo que tiene como consecuencia una cierta clausura o cierre del pensamiento, como plantea José Santos (2015). Obviamente, una filosofía así no es a la que se refiere Sylvia Eyzaguirre, sino a una que rompa estas limitaciones a través del desarrollo del pensamiento crítico, que incluso pueda poner en cuestión la propia práctica de la enseñanza que se ha venido desarrollando.

Me parece que no será fácil que quienes toman las decisiones curriculares en Chile acepten las recomendaciones para la política pública con las que concluye su texto Sylvia Eyzaguirre, pero me parece que los argumentos reales de por qué no es aceptada la filosofía en todos los niveles escolares debería ponerse en el tapete. Por lo menos deberíamos exigirlo como sociedad, pues si la evidencia indica sus bondades, entonces no habría razones para no incorporarla. No olvidar, entonces, que la lucha es por el contenido, nuestros contenidos. 


\section{Referencias bibliográficas}

Barceló, Joaquín (1982), "La actividad filosófica en Chile en la segunda mitad del siglo XX”, en Astorquiza, F. (Dir.), Bio-Bibliografia de la Filosofia en Chile, desde el siglo XVI hasta 1980. Santiago: Universidad de Chile/ Instituto Profesional de Santiago, pp. 107-112.

Eyzaguirre, Silvia (2018), "El rol de la filosofía en el desarrollo del pensamiento crítico", Puntos de Referencia $\mathrm{N}^{\circ}$ 485. Santiago: Centro de Estudios Públicos.

Gaete, Marcela (ed.) (2007), Arte y filosofía en el currículo escolar. Entre el desarraigo y el olvido. Santiago: Facultad de Filosofía y Humanidades. Universidad de Chile.

Sánchez, Cecilia (1992), Una disciplina de la distancia: institucionalización universitaria de los estudios filosóficos en Chile. Santiago: Chile América, CESOC.

Santos, José (2015), Cartografía crítica. El quehacer profesional de la filosofía en Chile. Santiago: Libros de la Cañada.

Tardif, Maurice (2004), Los saberes de los Docentes y su Desarrollo Profesional. Madrid: Narcea.

Tenti, E. (1998), “La escuela constructora de subjetividad”. En Filmus, D., G. Figerio y G. Tiramonti, Las transformaciones educativas en Iberoamérica. Tres desafios: Democracia, desarrollo e integración. Argentina: Troquel, pp. 110126. 